\title{
Introducing Hospital Pharmacy: An innovative approach
}

Author: Natalie Lewis, Julie Brooks and Lucy Paskin, Teacher Practitioner Team, Aston University

Background: Employers and the General Pharmaceutical Council recognise that work based learning is critical to pharmacy teaching. It is vital early in undergraduate study that the diverse role of the hospital pharmacist is explored; allowing academic knowledge to be contextualised and work based learning optimised. An alternative to the traditional small group "tour" was required to deliver a quality assured and cost effective hospital pharmacy introduction.

Method: A professional, bespoke, pharmacy focussed film was created at a cost of $£ 3,000$ (includes professional media team and teacher practitioner time). The film captures a clinical pharmacist working as part of the multidisciplinary team at ward level; enabling visualisation of the role of the hospital clinical pharmacist. The dispensary, aseptic manufacture, medicines information, purchasing and stores (robotic and traditional) were included to give an overview of hospital pharmacy.

The film was integrated into an interactive lecture for stage one students $(n=149)$ which utilised individual electronic voting systems (IEVS) to gain students' response and expand key points. This was also used to evaluate engagement with the session (response rate to questions and evaluative questions).

Results: Students $(n=90)$ demonstrated a high level of engagement within the session with $91 \%(n=82)$ engaging with every question as measured by the IEVS. From the evaluative questions $82 \%(n=69 / 84)$ felt the film provided enough insight into hospital pharmacy for it to act as preparation for subsequent work based learning. No prior experience within hospital pharmacy had been gained by $91 \%$ $(n=79 / 87)$ of the students.

Conclusion: The two hour session effectively replaced the traditional small group "tour" which totalled 80 hours/year. Time saved has allowed teacher practitioner involvement in other university activities maintaining students' engagement with practice pharmacists. The reduction of student traffic through hospital departments has had a positive impact on working efficiency within the pharmacy departments. 